\title{
Analisis Suseptibilitas Magnetik Tanah Lapisan Atas sebagai Parameter Kesuburan Tanah pada Lahan Pertanian
}

\author{
Bagindo Ichsan Rangkuti*, Arif Budiman \\ Laboratorium Fisika Bumi, Jurusan Fisika \\ Fakultas Matematika dan Ilmu Pengetahuan Alam Universitas Andalas \\ Kampus Unand LimauManis, Padang, 25163 Indonesia \\ *bagindoichsanr@gmail.com
}

\begin{abstract}
ABSTRAK
Telah dilakukan analisis suseptibilitas magnetik tanah lapisan atas sebagai parameter kesuburan tanah pada lahan pertanian. Pengambilan sampel dilakukan di Alahan Panjang, Kecamatan Lembah Gumanti, Kabupaten Solok dengan 4 lahan pertanian yaitu bawang merah, cabai merah, kentang, dan tomat serta satu lahan yang belum dijadikan lahan pertanian (lahan kosong). Pengambilan sampel diambil pada kedalaman $20 \mathrm{~cm}$ dengan jarak 2 meter antara titik pengambilan sampel. Sampel diambil sebanyak 10 sampel pada setiap lahan sehingga diperoleh 50 sampel. Pengukuran suseptibilitas magnetik menggunakan MS2B Bartington Susceptibility Meter dengan dua frekuensi, yaitu $0,47 \mathrm{kHz}$ low frequency (LF) dan 4,7 kHz high frequency (HF). Pada lokasi lahan bawang merah memiliki nilai suseptibilitas magnetik $\left(\chi_{\mathrm{LF}}\right)$ dengan rata-rata $281,6 \times 10^{-8} \mathrm{~m}^{3} / \mathrm{kg}$, lahan cabai merah dengan rata-rata $376,3 \times 10^{-8} \mathrm{~m}^{3} / \mathrm{kg}$, lahan kentang dengan rata-rata $240,4 \times 10^{-8} \mathrm{~m}^{3} / \mathrm{kg}$, lahan tomat dengan rata-rata $244,9 \times 10^{-8} \mathrm{~m}^{3} / \mathrm{kg}, 1 \mathrm{ahan}$ kosong dengan rata-rata $789,8 \times 10^{-8} \mathrm{~m}^{3} / \mathrm{kg}$. Hasil uji XRF menunjukkan bahwa mineral magnetik yang terdapat pada semua lokasi lahan pengambilan sampel adalah hematit. Lahan kosong memiliki nilai $\chi_{\mathrm{FD}}(\%)$ kurang dari $2 \%$ dikatakan masih memiliki kesuburan tanah yang baik untuk bercocok tanam sedangkan lahan pertanian memiliki nilai $\chi_{\mathrm{FD}}(\%) 2-10 \%$ dikatakan telah mengalami penurunan kesuburan tanah untuk bercocok tanam.

Kata kunci : bulir superparamagnetik, suseptibilitas magnetik, Alahan Panjang
\end{abstract}

\section{ABSTRACT}

An analysis of the magnetic susceptibility of topsoil has been carried out as a parameter of soil fertility on agricultural land. Sampling was carried out in Alahan Panjang, Lembah Gumanti Subdistrict, Solok Regency with 4 agricultural lands, namely shallots, red chili, potatoes, and tomatoes and one land that had not yet been used as agricultural land (empty land). Sampling was taken at a depth of $20 \mathrm{~cm}$ with a distance of 2 meters at each sampling point. Samples were taken as many as 10 samples on each field to obtain 50 samples. Measurement of magnetic susceptibility using the Bartington Susceptibility Meter $M S 2 B$ with two frequencies, namely $0,47 \mathrm{kHz}$ low frequency $(L F)$ and 4,7 $\mathrm{kHz}$ high frequency $(H F)$. The location of shallots has a magnetic susceptibility value $\left(\chi_{L F}\right)$ with an average of $281,6 \times 10 \mathrm{~m}^{3} / \mathrm{kg}, \mathrm{red}$ chili fields with an average of $376,3 \times 10 \mathrm{~m}^{3} / \mathrm{kg}$, with an average potato field average $240,4 \times 10 \mathrm{~m}^{3} / \mathrm{kg}$, tomato land with an average of $244,9 \times 10 \mathrm{~m}^{3} / \mathrm{kg}$, empty land with an average of $789,8 \times 10 \mathrm{~m}^{3} / \mathrm{kg}$. The $X R F$ test results showed that the magnetic minerals found in all sampling locations were hematite. Land with a value of $\chi_{F D}(\%)$ of less than $2 \%$ still has good soil fertility for farming and soil with a value of $\chi_{F D}$ (\%) $2-10 \%$ has experienced a decrease in soil fertility for farming.

Keywords : superparamagnetic grain, magnetic susceptibility, Alahan Panjang

\section{PENDAHULUAN}

Tanah merupakan bahan-bahan mineral yang terdapat di permukaan bumi sebagai hasil pelapukan batuan dan bahan-bahan organik yaitu sisa-sisa tumbuhan dan hewan (Yuliprianto, 2010). Tanah berperan sebagai media tempat tumbuhnya perakaran dan penyedia unsur hara bagi tanaman (Rachman dkk, 2017). Di dalam tanah terdapat unsur hara makro dan unsur hara mikro. Unsur hara makro dibutuhkan dalam jumlah yang banyak untuk pertumbuhan tanaman sedangkan unsur hara mikro dibutuhkan dalam jumlah yang sedikit untuk pertumbuhan tanaman. Meskipun dibutuhkan dalam jumlah yang sedikit unsur hara mikro memiliki peranan penting dalam pertumbuhan tanaman (Syekhfani, 2012).

Salah satu unsur mikro yang penting untuk pertumbuhan tanaman adalah $\mathrm{Fe}$. $\mathrm{Fe}$ berpartisipasi dalam mempengaruhi struktur tanah dan kesuburan tanah (Glinski dan Horabik, 2011). Fe berperan penting untuk pertumbuhan tanaman yaitu sebagai sintesis klorofil, penyusun penting dari enzim, sebagai akseptor oksigen dalam perubahan $\mathrm{Fe}^{2+}$ menjadi $\mathrm{Fe}^{3+}$, dan berperan dalam sistem redoks metabolisme $\mathrm{N}$ dan $\mathrm{S}$. Kekurangan $\mathrm{Fe}$ pada tanaman 
menyebabkan timbulnya warna bintik-bintik kuning pada daun muda (chlorosis), pertumbuhan tanaman akan terhenti, daun berguguran serta dapat mengakibatkan kematian (Sudarmi, 2013). Keunggulan $\mathrm{Fe}$ dibandingkan dengan unsur hara lainnya adalah Fe memiliki sifat magnetik yang jauh lebih besar karena sifatnya yang feromagnetik.

Kandungan $\mathrm{Fe}$ dalam tanah dapat diidentifikasi menggunakan Spektrometri X-Ray Fluorescence (XRF). XRF merupakan alat yang digunakan untuk menganalisis komposisi kimia beserta konsentrasi unsur-unsur yang terkandung dalam suatu sampel. Selain iu, metode suseptibilitas magnetik dapat juga digunakan untuk mengidentifikasi kandungan Fe dengan menganalisis nilai suseptibilitas mineral magnetik yang terkandung dalam sampel. Pada metode bisa diketahui keberadaan bulir superparamagnetik yang terdapat pada tanah permukaan. Keberadaan bulir tersebut dapat diketahui dari nilai suseptibilitas bergantung frekuensi (frequency dependent susceptibility), $\chi_{\mathrm{FD}}(\%) . \chi_{\mathrm{FD}}(\%)$ merupakan perbedaan relatif antara suseptibilitas frekuensi rendah $\chi_{\mathrm{LF}}$ dengan frekuensi tinggi $\chi_{\mathrm{HF}}$. Semakin tinggi nilai $\chi_{\mathrm{FD}}(\%)$ maka semakin banyak keberadaan bulir superparamagnetik pada tanah. Tanah yang mengandung bulir superparamagnetik banyak mengandung butiran halus.

Beberapa peneliti telah menggunakan metoda suseptibilitas magnetik ini yaitu Haris (2013) telah melakukan penelitian perubahan sifat fisika tanah akibat pemakaian pupuk kimia dengan hasil dimana nilai suseptibilitas magnetik pada lahan yang sudah dijadikan lahan pertanian lebih rendah dari pada lahan yang belum dijadikan lahan pertanian. Pemakaian pupuk kimia pada lahan yang telah dijadikan lahan pertanian menyebabkan mineral magnetik dalam tanah berkurang. Nilai $\chi_{\mathrm{FD}}(\%)$ pada tanah yang belum dijadikan lahan pertanian memiliki nilai sebesar $\leq 2 \%$ sedangkan pada lahan yang telah dijadikan lahan pertanian memiliki nilai sebesar 4,86 \% untuk lahan jagung dan 3,33\% untuk lahan cabai. Hikma, dkk (2015) juga telah melakukan penelitian analisis sifat fisika tanah di dua perkebunan apel melalui pengukuran suseptibilitas magnetik tanah. Hasil penelitian menunjukkan bahwa di perkebunan dengan pola persebaran nilai suseptibilitas magnetik tanah yang lebih tinggi memproduksi diameter apel yang lebih besar. Siqueira, dkk (2016) telah melakukan penelitian analisis suseptibilitas magnetik tanah untuk mengkarakterisasi lahan dengan potensi produksi tebu yang berbeda. Hasil penelitian menunjukkan lahan yang memiliki suseptibilitas magnetik tanah yang tinggi memproduksi tebu yang lebih banyak.

Nagari Alahan Panjang adalah salah satu sentra produksi hortikultura bagi Kabupaten Solok dan merupakan yang terbesar di Sumatera Barat dimana mayoritas mata pencarian penduduknya adalah petani. Topografi Nagari Alahan Panjang Kecamatan Lembah Gumanti Kabupaten Solok terletak didaerah perbukitan dan merupakan daerah musim hujan dengan ratarata curah hujan $2600 \mathrm{~mm} /$ tahun yang terletak pada ketinggian yaitu 1.400-1.600 meter dari permukaan laut. Hampir semua jenis hortikultura bisa dibudidayakan di tempat tersebut. Oleh karena menjadi sentra holtikultura terbesar di Sumatera Barat, keadaan tanah di Nagari Alahan Panjang bisa dikatakan baik untuk bercocok tanam.

Pada penelitian ini akan dilakukan analisis suseptibilitas magnetik tanah di Alahan Panjang, yang sebelumnya belum pernah dilakukan. Penelitian dilakukan pada lima lahan yang terdiri dari empat lahan pertanian yaitu lahan bawang merah, cabai merah, kentang, tomat dan satu lahan yang belum dijadikan lahan pertanian (lahan kosong).

\section{METODE}

\subsection{Teknik Pengambilan Sampel}

Pengambilan sampel dilakukan pada lima lahan (Gambar 1) yang terdiri dari empat lahan pertanian yaitu lahan bawang merah (kode sampel B), cabai merah (kode sampel C), kentang (kode sampel K), tomat (kode sampel T), dan satu lahan kosong (kode sampel P). Pada setiap lahan, sampel diambil pada 10 titik dengan jarak antar titik 2,0 $\mathrm{m}$ dan koordinat pengambilan sampel ditentukan dengan menggunakan GPS. Selanjutnya pipa PVC ditancapkan ke tanah pada kedalaman $20 \mathrm{~cm}$. Kemudian tanah yang berada di ujung pipa diambil secukupnya, lalu dimasukkan ke dalam plastick ziplock yang telah diberi tanda. Sampel yang telah diambil dikeringkan pada temperatur kamar selama 24 jam. Pengeringan sampel dilakukan agar uap air yang terkandung pada sampel tanah berkurang. Sampel tanah yang sudah 
dikeringkan tersebut lalu digerus dan kemudian diayak menggunakan saringan 100 mesh. Sebanyak 7,37 g sampel tanah tersebut dimasukkan ke dalam sample holder. Pengukuran suseptibilitas magnetik menggunakan MS2B Bartington Susceptibility Meter dengan dua frekuensi, yaitu $0,465 \mathrm{kHz}$ low frequency (LF) dan 4,65 kHz high frequency (HF). Pengukuran nilai suseptibilitas menggunakan 15 arah pengukuran. Data dari hasil pengukuran dicatat, kemudian diolah menggunakan program Matlab 2015a dan microsoft excel.

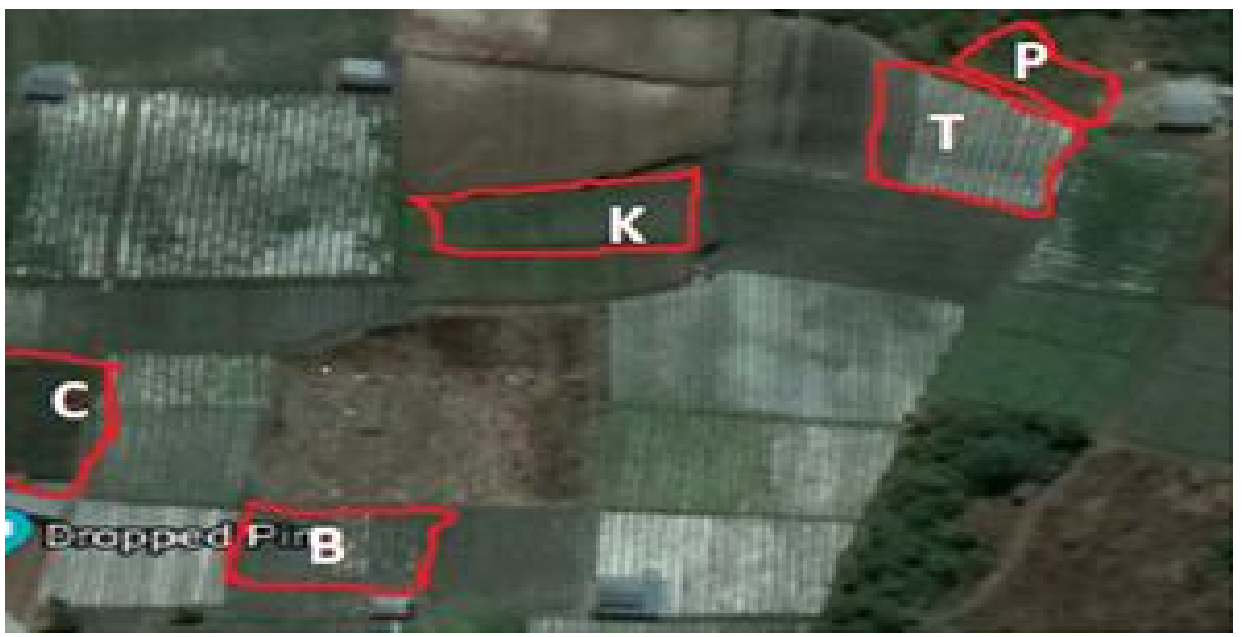

Gambar 1 Lokasi Pengambilan Sampel

Pengukuran nilai suseptibilitas magnetik dalam dua frekuensi dimaksudkan untuk memperoleh nilai frequency dependent susceptibility $\chi_{\mathrm{FD}}(\%) \cdot \chi_{\mathrm{FD}}(\%)$ merupakan perubahan suseptibilitas dengan frekuensi rendah $\chi_{\mathrm{LF}}$ dan frekuensi tinggi $\chi_{\mathrm{LF}}$ seperti yang ditunjukkan sesuai Persamaan (1).

$$
\chi_{F D} \%=\frac{\left|\chi_{L F}-\chi_{H F}\right|}{\chi_{L F}} \times 100
$$

Nilai $\chi_{\mathrm{FD}}(\%)$ dapat digunakan untuk mengetahui keberadaan bulir superparamagnetik yang terdapat pada sampel. Interpretasi nilai $\chi_{\mathrm{FD}}(\%)$ terhadap keberadaan bulir superparamagnetik dapat dilihat pada Tabel 1.

Tabel 1 Interpretasi nilai $\chi_{\mathrm{FD}}(\%)$

\begin{tabular}{cl}
\hline Nilai $\chi_{\mathbf{F D}}(\%)$ & \multicolumn{1}{c}{ Keterangan } \\
\hline $0,0-2,0$ & $\begin{array}{l}\text { Tidak ada atau mengandung kurang dari 10\% bulir } \\
\text { superparamagnetik }\end{array}$ \\
\hline $2,0-10,0$ & $\begin{array}{l}\text { Mengandung bulir superparamagnetik antara 10\% sampai } \\
\text { dengan 75\% yang merupakan campuran antara bulir } \\
\text { superparamagnetik yang berukuran halus dan kasar }\end{array}$ \\
\hline $10,0-14,0$ & $\begin{array}{l}\text { Keseluruhan atau mengandung lebih dari 75\% bulir } \\
\text { superparamagnetik }\end{array}$ \\
\hline
\end{tabular}

(Sumber: Dearing, 1999)

Tabel 1 tersebut menunjukkan bahwa semakin tinggi nilai $\chi_{\mathrm{FD}}(\%)$, maka semakin tinggi pula kandungan bulir superparamagnetiknya, namun nilai yang lebih besar dari $14 \%$ adalah sangat jarang dan sering dianggap kesalahan pengukuran (Dearing, 1999), sedangkan hubungan antara nilai $\chi_{\mathrm{FD}}(\%)$ terhadap bulir magnetik dapat dilihat pada Gambar 2. 


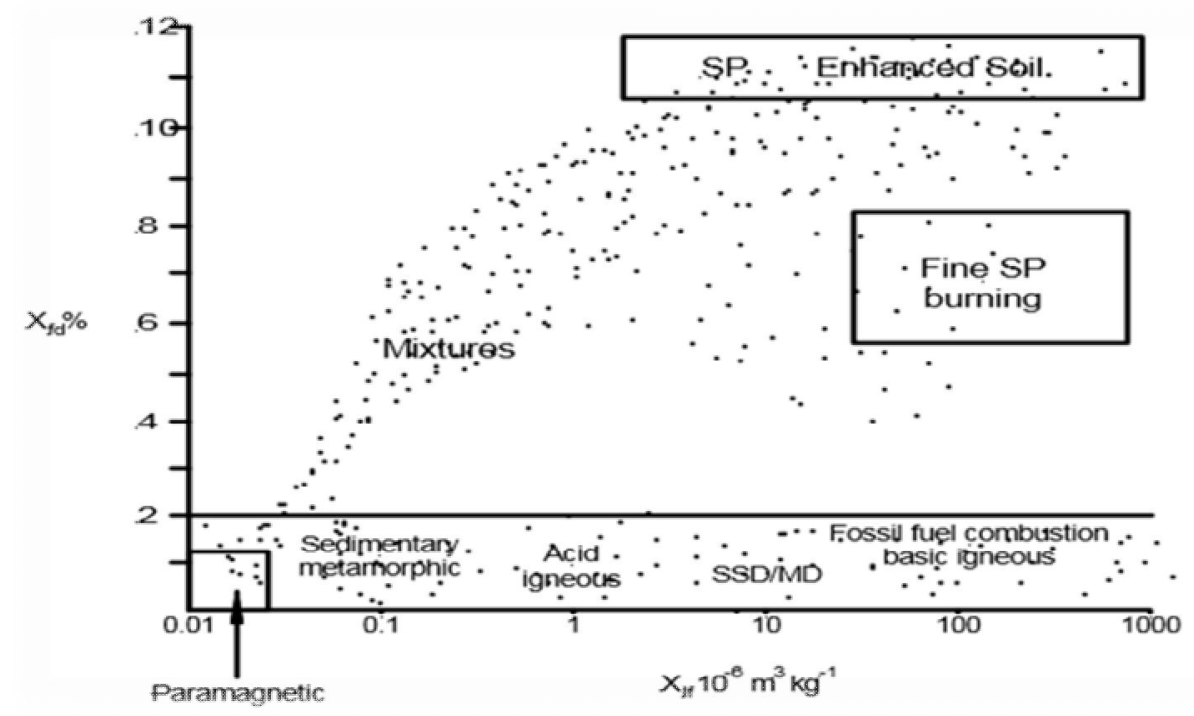

Gambar 2 Scattergram domain magnetik (Sumber : Dearing, 1999)

Penentuan jenis dan konsentrasi mineral yang terkandung pada sampel dilakukan menggunakan uji X-Ray Fluorescence (XRF). Pengujian ini dilakukan terhadap 5 sampel untuk mengetahui hubungan kandungan mineral magnetik terhadap nilai suseptibilitas magnetik sampel. Pemilihan kelima sampel berdasarkan nilai $\chi_{\mathrm{LF}}$ tertinggi pada masing-masing lokasi.

\section{HASIL DAN DISKUSI}

\subsection{Hubungan Nilai Suseptibilitas dengan Mineral Magnetik pada Sampel}

Nilai suseptibilitas magnetik sampel tanah dari 50 titik pengambilan sampel di lokasi yaitu pada pengukuran $\chi_{\mathrm{LF}}$ lahan bawang merah memiliki nilai suseptibilitas magnetik berkisar $155,2 \times 10^{-8} \mathrm{~m}^{3} / \mathrm{kg}$ sampai $334,3 \times 10^{-8} \mathrm{~m}^{3} / \mathrm{kg}$ dengan rata-rata $281,6 \times 10^{-8} \mathrm{~m}^{3} / \mathrm{kg}$, lahan cabai merah memiliki nilai suseptibilitas magnetik berkisar $327,9 \times 10^{-8} \mathrm{~m}^{3} / \mathrm{kg}$ sampai $439,6 \times 10^{-8} \mathrm{~m}^{3} / \mathrm{kg}$ dengan rata-rata $376,3 \times 10^{-8} \mathrm{~m}^{3} / \mathrm{kg}$, lahan kentang memiliki nilai suseptibilitas magnetik berkisar $165,0 \times 10^{-8} \mathrm{~m}^{3} / \mathrm{kg}$ sampai $310,8 \times 10^{-8} \mathrm{~m}^{3} / \mathrm{kg}$ dengan rata-rata $240,4 \times 10^{-8} \mathrm{~m}^{3} / \mathrm{kg}$, lahan tomat memiliki nilai suseptibilitas magnetik berkisar $133,1 \times 10^{-8} \mathrm{~m}^{3} / \mathrm{kg}$ sampai $298,3 \times 10^{-8} \mathrm{~m}^{3} / \mathrm{kg}$ dengan rata-rata $244,9 \times 10^{-8} \mathrm{~m}^{3} / \mathrm{kg}$, lahan kosong memiliki nilai suseptibilitas magnetik berkisar $344,3 \times 10^{-8} \mathrm{~m}^{3} / \mathrm{kg}$ sampai $1800,5 \times 10^{-8} \mathrm{~m}^{3} / \mathrm{kg}$ dengan rata-rata $789,8 \times 10^{-8} \mathrm{~m}^{3} / \mathrm{kg}$. Pada pengukuran $\chi_{\mathrm{HF}}$ lahan bawang merah memiliki nilai suseptibilitas magnetik berkisar $149,6 \times 10^{-8}$ $\mathrm{m}^{3} / \mathrm{kg}$ sampai $326,2 \times 10^{-8} \mathrm{~m}^{3} / \mathrm{kg}$ dengan rata-rata $270,4 \times 10^{-8} \mathrm{~m}^{3} / \mathrm{kg}$, lahan cabai merah memiliki nilai suseptibilitas magnetik berkisar $314,5 \times 10^{-8} \mathrm{~m}^{3} / \mathrm{kg}$ sampai $428,2 \times 10^{-8} \mathrm{~m}^{3} / \mathrm{kg}$ dengan ratarata $364,7 \times 10^{-8} \mathrm{~m}^{3} / \mathrm{kg}$, lahan kentang memiliki nilai suseptibilitas magnetik berkisar $161,2 \times 10^{-8}$ $\mathrm{m}^{3} / \mathrm{kg}$ sampai $303,0 \times 10^{-8} \mathrm{~m}^{3} / \mathrm{kg}$ dengan rata-rata $234,7 \times 10^{-8} \mathrm{~m}^{3} / \mathrm{kg}$, lahan tomat memiliki nilai suseptibilitas magnetik berkisar $129,3 \times 10^{-8} \mathrm{~m}^{3} / \mathrm{kg}$ sampai $286,0 \times 10^{-8} \mathrm{~m}^{3} / \mathrm{kg}$ dengan rata-rata $239,3 \times 10^{-8} \mathrm{~m}^{3} / \mathrm{kg}$, lahan kosong memiliki nilai suseptibilitas magnetik berkisar $339,0 \times 10^{-8}$ $\mathrm{m}^{3} / \mathrm{kg}$ sampai $1772,7 \times 10^{-8} \mathrm{~m}^{3} / \mathrm{kg}$ dengan rata-rata $780,0 \times 10^{-8} \mathrm{~m}^{3} / \mathrm{kg}$. Berdasarkan nilai-nilai suseptibilitas di atas, diperkirakan bahwa sampel-sampel dari kedua lokasi mengandung mineral magnetik yaitu hematit $\left(\mathrm{Fe}_{2} \mathrm{O}_{3}\right)$ (Mullins, 1997; Hunt, dkk, 1995). Pada penelitian ini menggunakan perhitungan suseptibilitas massa. Batasan nilai suseptibilitas volum dikonversi menjadi suseptibilitas massa dengan massa jenis sampel $450 \mathrm{kgm}^{-3}$. Hasil konversi tersebut dapat dilihat pada Tabel 2.

Berdasarkan Tabel 2 dapat dilihat bahwa hampir semua sampel nilai suseptibilitas magnetiknya dikontrol oleh mineral paramagnetik dan ferimagnetik kecuali 3 sampel suseptibilitas magnetiknya dikontrol oleh ferimagnetik yaitu pada sampel P4, P5, dan P10. 
Tabel 2 Nilai suseptibilitas batuan dan mineral pengontrolnya

\begin{tabular}{ccc}
\hline $\begin{array}{c}\text { Suseptibilitas } \\
\text { volum, } \boldsymbol{\kappa} \\
(\times \mathbf{1 0}-\mathbf{S I})\end{array}$ & $\begin{array}{c}\text { Suseptibilitas massa, } \\
\chi_{\mathbf{L F}} \\
\left(\times \mathbf{1 0} \mathbf{~}^{\mathbf{3}} \mathbf{~ k g}^{-\mathbf{1}}\right)\end{array}$ & Mineral Pengontrol \\
\hline $0,5<\kappa$ & $\chi<110$ & Paramagnetik \\
\hline $0,5<\kappa<5$ & $110<\chi<1100$ & $\begin{array}{c}\text { Paramagnetik dan } \\
\text { ferimagnetik }\end{array}$ \\
\hline$\kappa>5$ & $\chi>1100$ & Ferimagnetik \\
\hline
\end{tabular}

Penentuan jenis dan konsentrasi mineral yang terkandung pada sampel dilakukan menggunakan uji XRF. Sampel yang diuji merupakan sampel dengan nilai suseptibilitas magnetik tertinggi pada setiap lahan. Hasil uji XRF menunjukkan mineral magnetik yang terkandung dalam sampel hanya $\mathrm{Fe}_{2} \mathrm{O}_{3}$ (hematit), hal ini sesuai dengan perkiraan berdasarkan nilai suseptibilitas magnetik sampel. Menurut Tarling dan Hrouda (1993), nilai suseptibilitas magnetik mineral dalam suatu batuan dikontrol oleh sifat mineralnya yaitu ferimagnetik dan paramagnetik. Hal ini dibuktikan dengan hasil uji XRF bahwa dalam sampel di samping terkandung mineral bersifat ferimagnetik, juga terdapat mineral yang bersifat paramagnetik seperti $\mathrm{Al}_{2} \mathrm{O}_{3}, \mathrm{CaO}, \mathrm{TiO}_{2}, \mathrm{~K}_{2} \mathrm{O}$ dan diamagnetik seperti $\mathrm{SiO}_{2}$ dan $\mathrm{P}_{2} \mathrm{O}_{5}$. Keberadaan mineral diagmanetik tidak akan mempengaruhi nilai suseptibilitas karena memiliki nilai suseptibilitas negatif.

\subsection{Analisis Hubungan Nilai Suseptibilitas dengan Kandungan Fe}

Dalam tanah, kadar normal kandungan Fe berkisar antara 10000 ppm sampai 100.000 ppm (Mengel dan Kirby, 1987). Berdasarkan Tabel 2 dapat dilihat bahwa nilai konsentrasi Fe (ppm) yang diperoleh melebihi kadar normal pada semua sampel. Oleh karena itu, bisa dikatakan bahwa unsur hara pada tanah tidak dalam keadaan seimbang atau berlebih Fe. Oleh karena itu diperlukan pemberian pupuk urea guna menyediakan unsur makro seperti N, P, K agar tanaman menyerap unsur hara yang seimbang. Dengan demikian tempat pengambilan sampel masih memiliki kesuburan tanah yang baik untuk bercocok tanam. Tempat pengambilan sampel merupakan daerah yang cukup sering terjadinya hujan. Hal inilah yang diduga menyebabkan konsentrasi Fe dalam tanah melebihi kadar normal.

Tabel 3 Nilai suseptibilitas magnetik dan konsentrasi Fe

\begin{tabular}{cccc}
\hline No & $\begin{array}{c}\text { Kode } \\
\text { Sampel }\end{array}$ & $\chi_{\mathbf{L F}}\left(\times \mathbf{1 0}^{-\mathbf{8}} \mathbf{m}^{\mathbf{3}} \mathbf{k g}\right)$ & $\begin{array}{c}\text { Konsentrasi } \\
\mathbf{F e}(\mathbf{p p m})\end{array}$ \\
\hline 1 & B5 & 344,2 & 187.200 \\
2 & C9 & 439,6 & 129.600 \\
3 & K8 & 310,8 & 143.100 \\
4 & T4 & 298,3 & 156.900 \\
5 & P10 & 1800,5 & 410.100 \\
\hline
\end{tabular}

Bisa dilihat juga bahwa, nilai suseptibilitas magnetik pada sampel T4 memiliki nilai yang terendah dan yang tertinggi pada sampel P10. Pada sampel C9 memiliki konsentrasi Fe terendah tetapi nilai suseptibilitas magnetiknya lebih tinggi dibandingkan dengan sampel K8 dan T4. Hal ini diduga karena selisih perbedaan konsentrasi Fe pada ketiga sampel tersebut yang tidak begitu signifikan, sedangkan selisih perbedaan kosentrasi Fe pada sampel P10 dengan yang lainnya sangat signifikan. Oleh karena itu masih bisa dikatakan semakin tinggi

nilai suseptibilitas maka semakin tinggi pula kandungan Fe dalam tanah. Pemakaian lahan secara berulang dengan tanaman yang sama menyebabkan penyerapan hara oleh tanaman selalu sama (Rosmarkam dan Yuwono, 2002). Begitu juga dengan penyerapan Fe oleh tanaman pada tanah yang ditanami dengan tanaman yang selalu sama. Hal ini jugalah yang membuat kandungan Fe pada setiap lahan berbeda-beda meskipun lahan berdekatan. Kandungan Fe pada lahan pertanian lebih tinggi dibandingkan lahan kosong hal ini disebabkan oleh penyerapan $\mathrm{Fe}$ oleh tanaman pada lahan pertanian lebih tinggi dibandingkan lahan kosong. 


\subsection{Analisis Hubungan $\chi_{\mathrm{FD}}(\%)$ dengan Kesuburan Tanah}

Berdasarkan Gambar 3 terlihat bahwa semua sampel memiliki nilai $\chi_{\mathrm{FD}}(\%)$ kecil dari $10 \%$. Pada lahan pertanian semua sampel memiliki nilai $\chi_{\mathrm{FD}}(\%)$ kecil dari $2-10 \%$ sedangkan pada lahan kosong semua sampel memiliki nilai $\chi_{\mathrm{FD}}(\%)$ kecil dari $2 \%$. Keberadaan bulir superparamagnetik pada tanah mengindikasikan bahwa keseluruhan tanah memiliki butiran yang halus. Semakin banyak bulir superparamagnetik yang terkandung dalam tanah, semakin banyak butiran halus yang dimiliki oleh tanah tersebut (Pratiwi dkk, 2016).

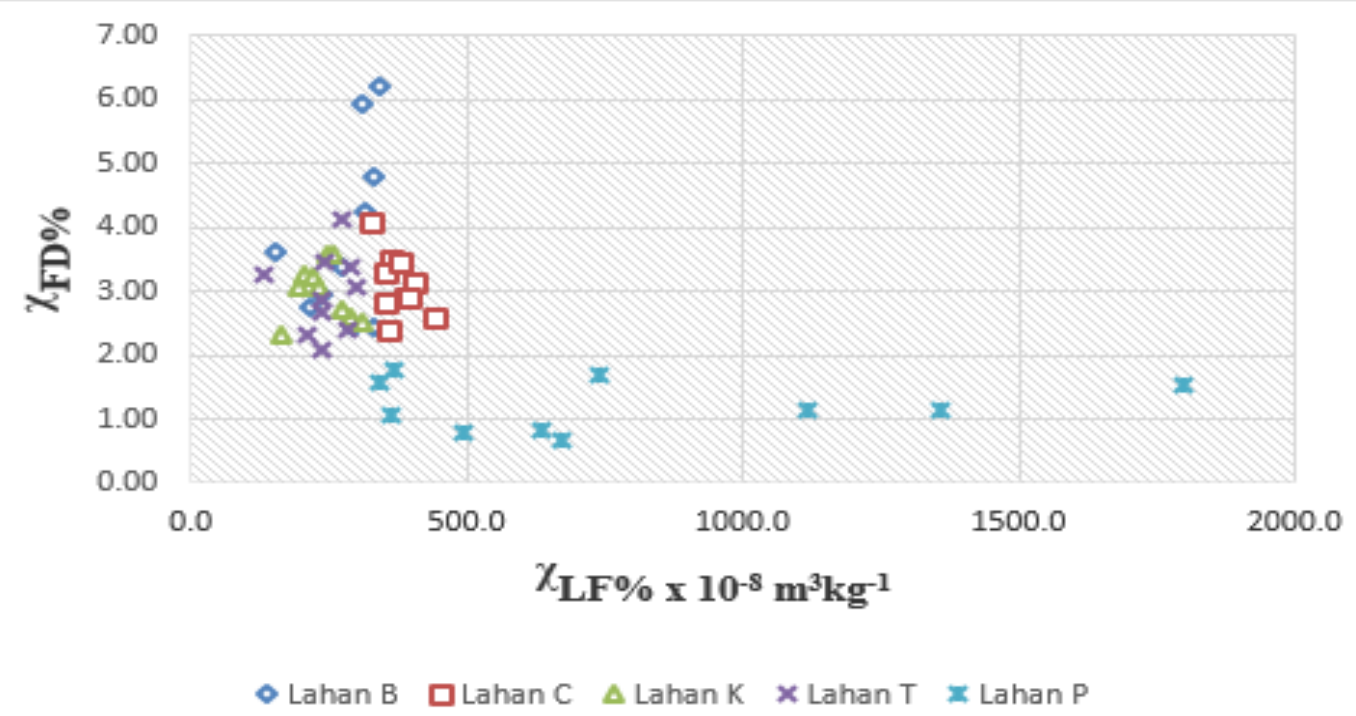

Gambar 3 Grafik hubungan antara nilai suseptibilitas magnetik terhadap $\chi_{\mathrm{FD}}(\%)$

Butiran halus pada lahan pertanian lebih banyak dibandingkan dengan lahan kosong. Hal ini disebabkan karena penyiraman yang rutin dilakukan pada lahan pertanian menyebabkan tingkat kelekatan tanah oleh air berkurang. Penyerapan unsur hara oleh lahan pertanian lebih tinggi dibandingkan dengan lahan kosong. Hal inilah yang menyebabkan unsur hara pada lahan pertanian berkurang sehingga lahan pertanian mengalami penurunan kesuburan tanah. Oleh karena itu bisa dikatakan tanah dengan nilai $\chi_{\mathrm{FD}}(\%)$ kurang dari $2 \%$ masih memiliki kesuburan tanah yang baik untuk bercocok tanam dan tanah dengan nilai $\chi_{\mathrm{FD}}(\%) 2-10 \%$ telah mengalami penurunan kesuburan tanah untuk bercocok tanam.

\section{KESIMPULAN}

Berdasarkan tempat pengambilan sampel, tanah memiliki kandungan Fe yang berlebih sehingga dikhawatirkan tanaman menyerap Fe terlalu banyak yang menyebabkan terhambatnya penyerapan unsur hara yang lainnya. Oleh karena itu diperlukan pemberian pupuk urea guna menyediakan unsur makro seperti N, P, K agar tanaman menyerap unsur hara yang seimbang.

Butiran halus pada lahan pertanian lebih banyak dibandingkan dengan lahan kosong. Hal ini disebabkan karena penyiraman yang rutin dilakukan pada lahan pertanian menyebabkan tingkat kelekatan tanah oleh air berkurang. Penyerapan unsur hara oleh lahan pertanian lebih tinggi dibandingkan dengan lahan kosong. Hal inilah yang menyebabkan unsur hara pada lahan pertanian berkurang sehingga lahan pertanian mengalami penurunan kesuburan tanah. Oleh karena itu bisa dikatakan lahan pertanian telah mengalami penurunan kesuburan tanah sedangkan lahan kosong masih memiliki kesuburan tanah yang baik.

\section{DAFTAR PUSTAKA}

Almiati, R., dan Agustin E., Analisis Kesuburan Tanah dan Residu Pemupukan pada Tanah dengan Menggunakan Metode Kemagnetan Batuan, Jurnal Ilmu dan Inovasi Fisika, Jurusan Fisika Universitas Padjajaran, 1, 2017.

Dearing, J., Environmental Magnetic Suseptibility Using the Bartington MS2 System, Chi Publishing, England, 1999. 
Haris, V., Studi Awal Perubahan Sifat Magnetik Tanah Akibat Pemakaian Pupuk Kimia, Jurnal Sainstek, Jurusan Tadris Fisika STAIN Batusangkar, 5, 2, 2013.

Hikma, R., Zulaikah, S., Budi, E., Analisis Sifat Tanah Perkebunan Apel Melalui Pengukuran Suseptibilitas Magnetik, XRF, dan GPR dan Implikasinya Pada Produksi Apel, Universitas Negeri Malang, Malang, 2015.

Kementrian Pekerjaan Umum, Rencana Tata Bangunan dan Lingkungan Kawasan Alahan Panjang Kabupaten Solok Sumatera Barat, 2013.

Mengel, K., dan Kirby E.A., Principle of Plant Nutrition $4^{\text {th }}$ Edition, International Potash Institute, Zug, Switzerland, 1987.

Pratiwi, R. A., Prakoso, A. G., Darmasetiawan, R., Agustine, E., Kirana, K. H., Fitriani, D., Identifikasi Sifat Magnetik Tanah di Daerah Tanah Longsor, Prosiding Seminar Nasional Fisika (E-journal) SNF2016, 5, 182-187, 2016.

Rachman, A., Sutono, Irawan, Suastika, W.I., Indikator Kualitas Tanah pada Lahan Bekas Penambangan, Jurnal Sumber Daya Lahan, Balai Penelitian Tanah, 11, 2017.

Rosmarkam, A., dan Yuwono, N.W., Ilmu Kesuburan Tanah, Kanisius, Yogyakarta, 2002.

Cahyono, O, Ilmu Tanah, Universitas Tunas Pembangunan Surakarta, Yogyakarta, 2014.

Siqueira, D.S., Marques Jr., J., Teixeira, D.D.B., Matias, S.S.R., Camargo, L.A., Pereira, G.T., Magnetic Susceptibility for Characterizing Areas with Different Potentials for Sugarcane Production. Pesq Agropec Bras, Elsevier, 51, 1349-1358, 2016.

Sudarmi, Pentingnya Unsur Hara Mikro Bagi Pertumbuhan Tanaman, Jurnal Widyatama, Fakultas Pertanian Universitas Veteran, 22, 178-183, 2013.

Syekhfani, Modul Kesuburan Tanah, Universitas Brawijaya, Malang, 2012.

Tarling, D.H. dan Hrouda, F., The Magnetic Anisotropy of Rock, Chapman \& Hall, London, United Kingdom, 1993.

Yulipriyanto, H., Biologi Tanah dan Strategi Pengelolaannya, Graha Ilmu., Yogyakarta, 2010. 